\title{
Dynamic simulation of existing buildings: considerations on the model calibration
}

\author{
Adriana Angelotti ${ }^{1}$, Micol Ballabio ${ }^{1}$, Livio Mazzarella ${ }^{1}$, Cristina Cornaro $^{2}$, Gianmarco Parente ${ }^{2}$, \\ Francesca Frasca ${ }^{3}$, Alessandro Prada ${ }^{4}$, Paolo Baggio ${ }^{4}$, Ilaria Ballarini ${ }^{5}$, Giovanna De Luca ${ }^{5}$, \\ Vincenzo Corrado \\ ${ }^{1}$ Dipartimento di Energia Politecnico di Milano, Milano, Italy \\ ${ }^{2}$ Dipartimento di Ingegneria dell'Impresa, Università degli Studi di Roma Tor Vergata, Roma, Italy \\ ${ }^{3}$ Dipartimento di Fisica, Università La Sapienza, Roma, Italy \\ ${ }^{4}$ Dipartimento di Ingegneria Civile, Ambientale e Meccanica, Università di Trento, Trento, Italy \\ ${ }^{5}$ Dipartimento Energia, Politecnico di Torino, Torino, Italy
}

\begin{abstract}
Dynamic energy simulation is increasingly used to design retrofit interventions in existing buildings. Energy savings are correctly predicted if the simulation model is carefully calibrated against measured data. In this study the same building storey is simulated by four different research groups with different dynamic simulation tools (EnergyPlus, TRNSYS, IDA ICE). The building envelope is simulated in free floating and a parametric analysis to envelope properties and users' behaviour is carried out. A set of basic information and measurements on the building is made available to three groups, while detailed information and measured data are provided to the fourth one. From the comparison among calibrated models it is concluded that, for a good calibration of a well-insulated building model, the absence of data regarding users' behaviour can be more critical than detailed measurements on the envelope properties.
\end{abstract}

\section{Introduction}

Building energy simulation (BES) is a powerful tool to design new energy efficient buildings and to identify energy retrofit and management interventions on existing ones. The second kind of application requires an accurate calibration of the simulation model against monitoring data, in order to trust the simulation results and achieve reliable predictions of the potential energy savings.

Although the calibration phase is crucial, a shared methodology is presently lacking: different approaches can be found in literature, regarding the kind and the quality of the metered data, the manual/automatic methodology, statistical indexes to be used, the uncertainty of the simulation tools etc. (Coakley et al., 2014; Fabrizio and Monetti, 2015, Prada et al. 2019). The few existing guidelines, such as ASHRAE Guideline 14 (ASHRAE, 2002), basically provide criteria and acceptable limits to consider a model calibrated. Within this framework, calibration is highly dependent on the user's skill and experience.

Multi-stage building energy model calibration, where the building and systems are divided into sub-models and then individually calibrated, has proved to achieve more accurate results than global calibration (Cacabelos et al., 2017). In a previous paper by the authors (Angelotti et al., 2018) the sub-modelling approach was brought to the single wall limit. A methodology to calibrate the thermo- physical properties of the walls was suggested as a first step towards the envelope calibration, in case detailed measurements related to heat flows, internal and surface temperatures are available. This approach is possible even within dynamic simulation tools requiring at least the modelling of a thermal zone, through a fictitious thermal zone method.

Clearly, in order to adopt a multi-stage calibration, measured data at a global level such as energy consumption are not sufficient. Measurements referring to individual components or behaviors are needed. Detailed measurements can refer to the building envelope thermal response, to the HVAC systems inputs/outputs, or even to the occupants' behaviour. The influence of the latter on the buildings energy performance is increasing, as building envelopes and systems become more and more optimised. The modelling of occupant behaviour has been the focus of the recently concluded IEA EBC Annex 66 (Yan et al., 2017).

Therefore, it may be argued that the quality and the quantity of measured data available to energy modellers orientate the modelling, the calibration approach and possibly the calibration results. This issue is confronted in this paper, where a comparison is carried out between models and calibrations based on the one side on detailed monitoring and on the other side on basic monitoring.

\section{Methodology}

In this study an intermediate floor of an existing residential building is simulated by four different research groups (PoliTO, PoliMI, UniTN, UniTOV), each using a dynamic simulation tool (EnergyPlus, TRNSYS and IDA ICE). PoliMI and UniTN both adopt TRNSYS 17.

The building envelope is simulated in free floating, as a first step of a multi-stage calibration approach that would include the HVAC system in a second phase. A set of basic information and measurements on the building is made available to three groups, while detailed information and measured data are provided to the fourth one. Starting from base models, calibrations are performed by minimizing the discrepancy with the indoor air temperature measured profile. Two groups adopt manual calibration, based on sensitivity analysis to envelope properties and occupants' behaviour parameters. The other two groups adopt automatic 
calibration by means of optimisation algorithms. Materials and methods for each research group are summarised in Table 1. The base and the calibrated models are then compared against each other. Calibrated models are tested on a second free floating period for validation.

Table 1: settings of the research.

\begin{tabular}{|c|c|c|c|}
\hline $\begin{array}{c}\text { Researc } \\
\text { h group }\end{array}$ & Tool & $\begin{array}{c}\text { Measures } \\
\text { data set }\end{array}$ & $\begin{array}{c}\text { Calibration } \\
\text { approach }\end{array}$ \\
\hline PoliTO & EnergyPlus & Basic & Manual \\
\hline PoliMI & TRNSYS 17 & Basic & Manual \\
\hline UniTOV & IDA ICE 4.8 & Basic & Automatic \\
\hline UniTN & TRNSYS 17 & Detailed & Automatic \\
\hline
\end{tabular}

Table 2: detailed and basic measurement data sets.

\begin{tabular}{|c|c|c|}
\hline Quantity & Detailed set & Basic set \\
\hline Meteorological data & Every 10 minutes & Every hour \\
\hline $\begin{array}{l}\text { Floor indoor air } \\
\text { temperature }\end{array}$ & $\begin{array}{l}\text { For different rooms } \\
\text { in Apartment A } \\
\text { For the main room } \\
\text { for Apartments B,C }\end{array}$ & $\begin{array}{l}\text { Average } \\
\text { among } \\
\text { apartments } \\
\mathrm{A}, \mathrm{B} \text { and } \mathrm{C} \\
\end{array}$ \\
\hline $\begin{array}{l}\text { Neighbouring floors } \\
\text { air temperature }\end{array}$ & $\begin{array}{l}\text { For every apartment } \\
\text { in the upper and in } \\
\text { the lower floor }\end{array}$ & $\begin{array}{l}\text { Upper floor } \\
\text { average } \\
\text { Lower floor } \\
\text { average }\end{array}$ \\
\hline $\begin{array}{c}\text { External wall } \\
\text { surface } \\
\text { temperatures/ heat } \\
\text { flow densities }\end{array}$ & Every 10 minutes & Not provided \\
\hline $\begin{array}{l}\text { Windows opening } \\
\text { switch }\end{array}$ & $\begin{array}{c}\text { Every } 10 \text { minutes } \\
\text { for every window in } \\
\text { apartment } \mathrm{A}\end{array}$ & Not provided \\
\hline $\begin{array}{l}\text { Mech. ventilation } \\
\text { supply temperature }\end{array}$ & $\begin{array}{c}\text { Every } 10 \text { minutes } \\
\text { for apartment } \mathrm{A}\end{array}$ & Not provided \\
\hline
\end{tabular}

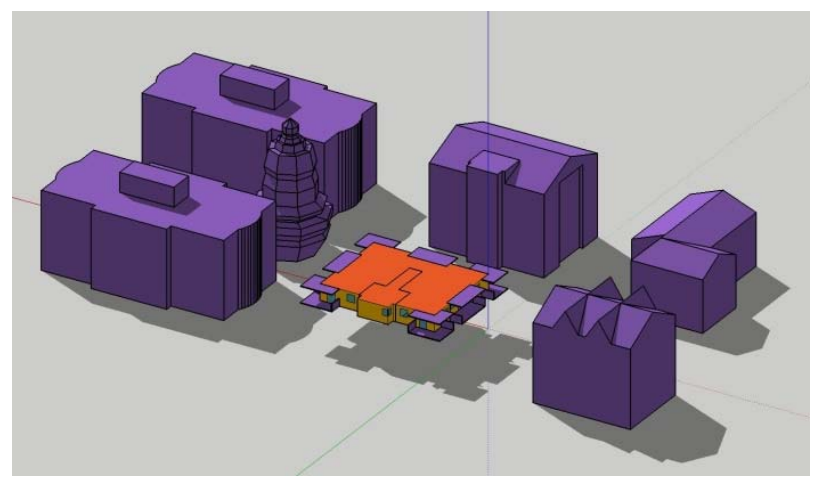

Figure 1: case study geometrical model.

\section{Case study}

The case study refers to a 5 storey residential building recently built in the province of Trento (Northern Italy, Alpine region). The building has a platform frame structure, a reinforced concrete stairwell and triple pane low-e windows. The heating system consists in a centralized condensing boiler supplying the radiant floor systems controlled by room thermostats. A mechanical ventilation system with heat recovery provides fresh air to the apartments with a constant airflow rate of 0.5 $\mathrm{ACH}$ during the heating period. During free-floating period, the mechanical ventilation still provides $0.5 \mathrm{ACH}$ but a manual damper at each apartment level allows to by-pass the heat recovery. No active cooling is provided in summertime. The occupants are free to open the windows and modify the thermostat set point.

A weather station close to the monitoring site collects the weather data every 10 minutes (Giovannini et al., 2013). A monitoring system measures the indoor air temperature and the thermal energy delivered daily by the radiant floor system in every apartment. In a few apartments more sensors were installed, allowing to measure surface temperatures and heat flow densities on the external wall, the indoor air temperature in different rooms, the mechanical ventilation air supply temperature and whether the windows are open or not.

For the purpose of this work, an intermediate floor of the building was chosen, where apartments named A, B and $\mathrm{C}$ are found. Measured data were grouped into a detailed and a basic data set, as shown in Table 2. The detailed data set was provided to UniTN, while the basic one to the other three research groups (Table 1).

\section{Modelling}

The building floor and the surrounding buildings were drawn in OpenStudio (Figure 1) and then the geometry was imported in each energy simulation environment. The research groups provided with the basic data set adopted a simple thermal zoning, modelling the building floor as 2 thermal zones, corresponding to the set of the 3 apartments and to the stairwell (see again Figure 1). In turn, the research group provided with the detailed data set defined 14 thermal zones, namely 5 zones in Apartment A, and 9 zones corresponding to Apartments $\mathrm{B}$ and $\mathrm{C}$ and the stairwell.

From the yearly meteorological data set, the month of October 2017 was chosen for simulations, considering the first week as the conditioning period for the building inertia and the remaining 3 weeks as the calibration period.

The base case models implemented constructions as described in design documentation (external walls with $\mathrm{U}$-value $=0.12 \mathrm{~W} /\left(\mathrm{m}^{2} . \mathrm{K}\right)$, triple-layers Argon filled lowe glazings with $\mathrm{U}$-value $\left.=0.6 \mathrm{~W} /\left(\mathrm{m}^{2} . \mathrm{K}\right)\right)$ and standard internal gains schedules for residential units (UNI/TS 11300-1, 2014). A constant mechanical ventilation flow rate equal to $0.5 \mathrm{ACH}$ was assigned. Window rollingshutters were supposed in use only during nigh time. Finally the air temperature profiles of the upper and lower floors were assigned as boundary conditions for the thermal zones. While UniTN modelled the internal partitions and used weather data every 10 minutes, the other groups ignored internal partitions and used hourly weather data.

\section{Statistical metrics}

The simulated indoor air temperature was compared with the measured one at every time step. The overall agreement between simulation results and measurements on the whole simulation period was evaluated through the Root Mean Squared Error, i.e.: 


$$
R M S E=\sqrt{\frac{\sum_{k}\left(M_{k}-S_{k}\right)^{2}}{N}}
$$

where $\mathrm{M}_{\mathrm{k}}$ and $\mathrm{S}_{\mathrm{k}}$ represent the measured and simulated temperature at time step $\mathrm{k}$, respectively. The model was considered calibrated if RMSE $\leq \sigma$, where the temperature measurement accuracy $\sigma$ is equal to $0.5^{\circ} \mathrm{C}$. In addition to RMSE, correlation plots of the simulated air temperature versus the measured one were drawn and the $R^{2}$ value of the linear interpolation was used as a simulation performance indicator.

\section{Manual calibration and sensitivity analysis}

PoliTO and PoliMI performed a manual calibration, preceded by a sensitivity analysis to the main building envelope parameters and user behaviour parameters reported in Table 3. The envelope parameters considered were: the thermal conductivity of the insulation layers, the thermal bridges overall correction, the g-value of the glazings and the internal mass. The latter, including the furniture, was modelled in different ways: through a multiplier of the indoor air volume capacity as suggested in (EN ISO 52016-1, 2017) and/or by introducing internal partitions. Regarding the occupants, the following parameters were considered: the internal gains daily profile, the use of rolling-shutters also during the day for solar shading when a minimum solar irradiance on the window is reached, the natural ventilation flow rate resulting from the windows opening. The latter was modelled following two approaches: opening according to a daily schedule or opening when outside air temperature reaches a threshold. In both cases, opening the windows determines given $\mathrm{ACH}_{\mathrm{NV}}$.

The parameters were varied one-at-a time and the sensitivity was evaluated by means of the following index $s$ :

$$
s=\frac{\Delta O}{\Delta I / I_{m}}
$$

where $O$ and $I$ are the output (indoor air temperature) and the input (parameter) respectively, the subscript $m$ indicates the mean value, and $\Delta O$ represents the root mean squared variation of the outputs at every time step, when the input is varied from the base value $I_{b}$ to the generic value $I$. It has to be mentioned that in the case of natural ventilation, $I$ is set equal to the total air changes, namely the sum of $\mathrm{ACH}_{\mathrm{MV}}$ and $\mathrm{ACH}_{\mathrm{NV}}$, so that $I_{b}=$ $\mathrm{ACH}_{\mathrm{MV}}=0.5$. The sensitivity index $s$ is thus dimensional $\left[{ }^{\circ} \mathrm{C}\right]$ but the input variation is normalised by the mean value, so that sensitivities to different quantities can be compared.

Following sensitivity analysis, the most influential parameters were combined and adjusted in order to reach the calibration target.

\section{Automatic calibration/basic data set}

UniTOV performed an automatic calibration by coupling IDA ICE with the optimization engine GenOpt, through the parametric runs macro. The objective function was identified in the RMSE for the apartments thermal zone, defined in (1). Since automatic calibration allows to easily vary more parameters compared to manual calibration, this potential was exploited. More in detail, the 3 steps of the internal gains schedule were allowed to vary, possibly leading to a profile very different from the base one. Moreover, the possibility that the threshold for shutters activation depends on the window orientation was tested.

\section{Automatic calibration/detailed data set}

First of all, UniTN used the detailed monitoring of the external walls to calibrate the thermal properties of the layers, operating at the single-wall level as in (Angelotti et al., 2018). The wall response in terms of inside and outside heat flow densities under imposed surface temperatures (equal to measured profiles in October 2017) was simulated. The wall properties were then optimised in order to reproduce the measured heat flow densities on both sides.

As a second step, the base building floor model was refined, taking into account the additional information on Apartment A derived from the detailed data set (Table 2), namely:

- windows are often open during the day;

- the mechanical ventilation air supply temperature is not equal to outdoor temperature, as if the occupants did not switch on the heat recovery by-pass.

Therefore, in the refined model the windows in

\begin{tabular}{|c|c|c|c|}
\hline & Parameter & Base value & Variation \\
\hline \multirow{4}{*}{$\frac{\check{0}}{\stackrel{0}{\circ}}$} & $\begin{array}{l}\text { Mineral wool/wood } \\
\text { fibres thermal } \\
\text { conductivity }\end{array}$ & $\begin{aligned} \lambda_{\mathrm{mw}} & =0.038 \mathrm{~W} /(\mathrm{m} . \mathrm{K}) \\
\lambda_{\mathrm{wf}} & =0.05 \mathrm{~W} /(\mathrm{m} . \mathrm{K})\end{aligned}$ & $+5 \% \div+20 \%$ \\
\hline & Thermal bridges & $\Psi \mathrm{L}=0$ & $\Psi \mathrm{L}=5 \div 15 \mathrm{~W} / \mathrm{K}$ \\
\hline & Glazings g-value & $\mathrm{g}=0.52$ & $\mathrm{~g}=0.34 \div 0.40$ \\
\hline & Internal mass & $\begin{array}{c}\text { Air capacity multiplier } \mathrm{ACM}=1 \\
\text { Partitions surf. } \mathrm{S}_{\mathrm{part}}=0 \\
\text { No furniture }\end{array}$ & $\begin{array}{c}\mathrm{ACM}=1 \div 10 \\
\mathrm{~S}_{\text {part }}=259 \mathrm{~m}^{2} \div 1034 \mathrm{~m}^{2} \text { (to include furniture) }\end{array}$ \\
\hline \multirow{3}{*}{ 芯 } & Internal gains schedule & standard (UNI 11300-1, 2014) & $\begin{array}{l}\text { a) reduced by factor } 5 \% \div 50 \% \\
\text { b) modified conserving daily energy gain }\end{array}$ \\
\hline & $\begin{array}{c}\text { Solar irradiance } \\
\text { threshold for shutters use }\end{array}$ & $\mathrm{G}_{\min }=1376 \mathrm{~W} / \mathrm{m}^{2}$ & $\mathrm{G}_{\min }=200 \div 300 \mathrm{~W} / \mathrm{m}^{2}$ \\
\hline & $\begin{array}{l}\text { Natural ventilation flow } \\
\text { rate }\end{array}$ & $\mathrm{ACH}_{\mathrm{NV}}=0$ & $\begin{array}{l}\mathrm{ACH}_{\mathrm{NV}}=0.5 \div 1.5 \\
\text { a) hourly schedule } \\
\text { b) when } \mathrm{T}_{\text {ext }}>\mathrm{T}_{\min }\end{array}$ \\
\hline
\end{tabular}

Table 3: parameters of the sensitivity analysis. 


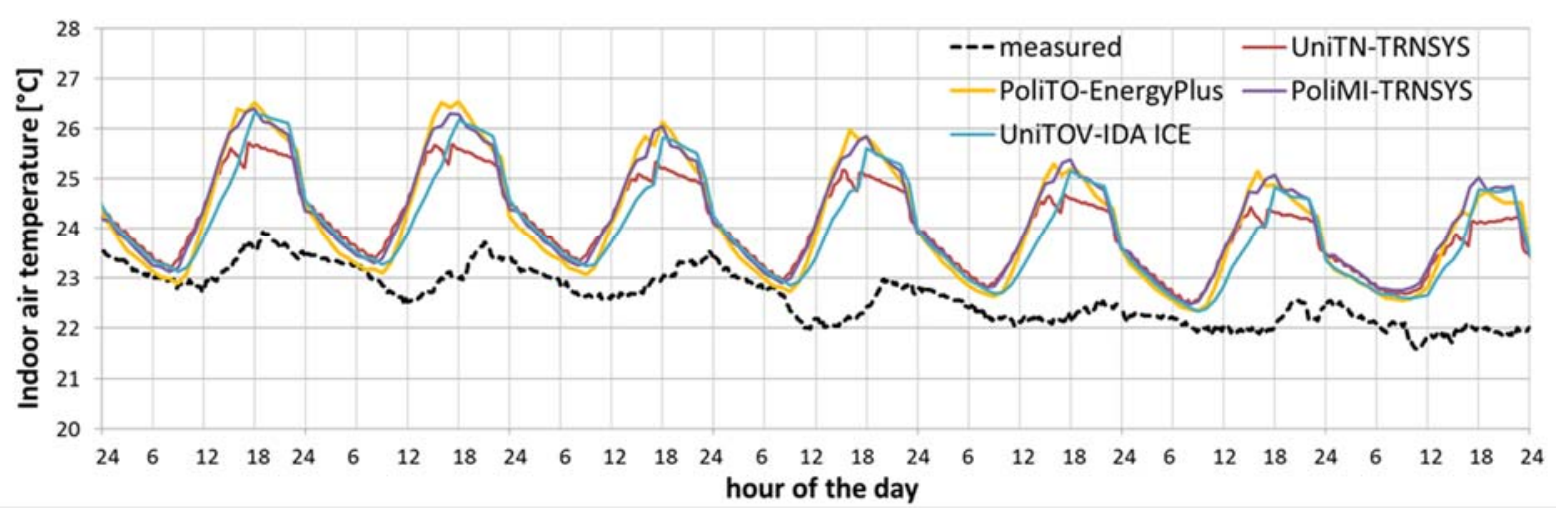

Figure 2: simulated (base models) and measured indoor air temperature ( $3^{\text {rd }}$ week October 2017)

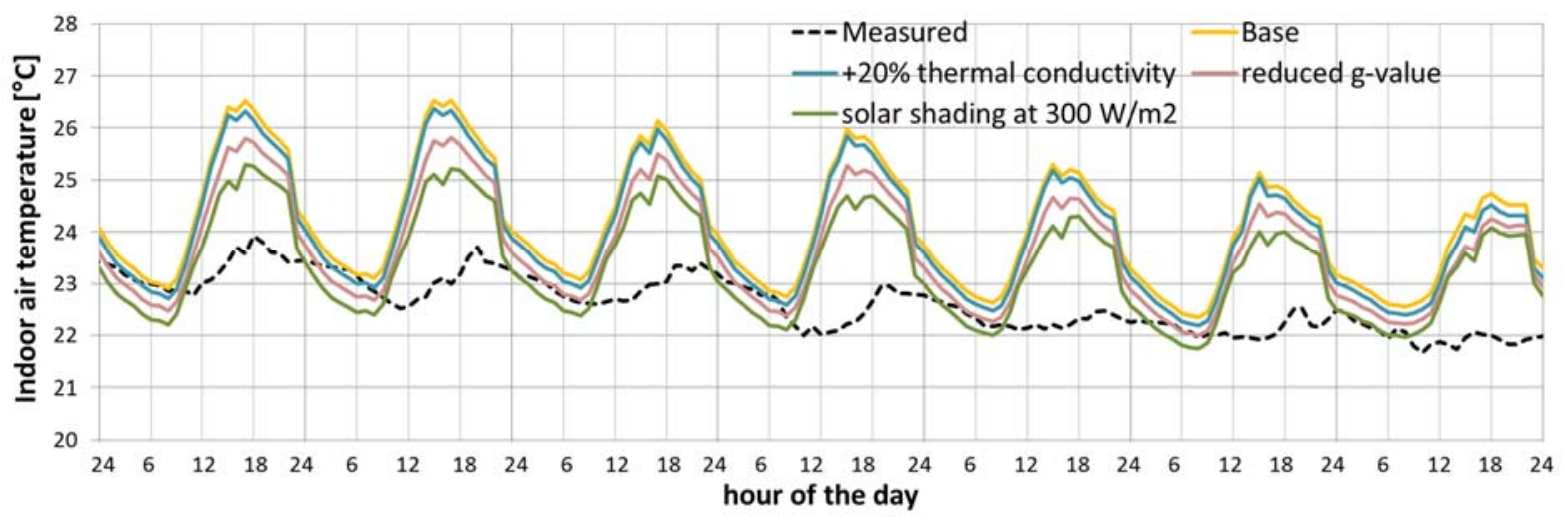

Figure 3: sensitivity analysis - PoliTO-EnergyPlus ( $3^{\text {rd }}$ week October 2017)

Apartment A are open according to the measured switch signals and the natural ventilation flow rate is calculated depending on the wind pressure and the temperature difference, following the approach by the standard (EN $15242,2007)$. As far as the mechanical ventilation in Apartment A is concerned, the measured air supply temperature profile is given as input. Finally the natural ventilation flow rates in Apartments $\mathrm{B}$ and $\mathrm{C}$ are modelled scaling the corresponding flow rate in Apartment A.

As a third step, automatic calibration on the refined model was carried out. Beside internal gains profiles, threshold irradiance for shutters activation for each apartment and indoor air volume capacitance multiplier, the calibration parameters are the windows opening angle in Apartment $\mathrm{A}$ and the natural ventilation flow rates scaling factors for Apartments $\mathrm{B}$ and $\mathrm{C}$. The objective function for the automatic calibration was identified in the sum of the RMSE of the different thermal zones.

\section{Validation}

The calibrated models were tested on a second period. Among the periods of the year when the building is in free floating, August 2018 was selected for validation. Being warmer and more sunny than October, it actually represents a challenge for the calibrated models.

\section{Results}

\section{Base models results}

The indoor air temperature during the $3^{\text {rd }}$ week of October obtained from the base models simulations is reported in Figure 2 together with the measured trend. The RMSE calculated over the calibration period for each base model is reported in Table 4. The outputs from the different simulation tools are generally coherent with each other's. Compared with the measured profile, they all overestimate the indoor air temperature mean value and variation amplitude; moreover, they anticipate the peaks. It is worth comparing the simulation outputs by UniTN and PoliMI, since they are both obtained through TRNSYS. The simulation output by UniTN is generally damped, especially in the warm peaks, with respect to the output obtained by PoliMI. This outcome can be attributed to the inertia of the partition walls that are modelled in the base case by UniTN, while they are not considered in the base case by PoliMI and the other groups.

Table 4: base models performance (October 2017)

\begin{tabular}{|c|c|c|}
\hline Research group & Tool & $\boldsymbol{R M S E}\left[{ }^{\circ} \mathbf{C}\right]$ \\
\hline PoliTO & EnergyPlus & 1.81 \\
\hline PoliMI & TRNSYS 17 & 1.76 \\
\hline UniTOV & IDA ICE 4.8 & 1.58 \\
\hline UniTN & TRNSYS 17 & 1.53 \\
\hline
\end{tabular}




\section{Manual calibration results}

The sensitivity analysis performed by PoliTO and PoliMI showed a modest influence of the external opaque envelope parameters, namely the thermal conductivity of the insulation layers and the thermal bridges correction. On the contrary reducing the glazing solar heat gain coefficient, introducing external solar shading, reducing/modifying the internal gains profile, adding internal mass and introducing natural ventilation during the day all impact on the simulation output. An example is shown in Figure 3, where the variation in the indoor air temperature profile during the $3^{\text {rd }}$ week of October 2017 for some parametric variations brought to the base model is reported (PoliTO-EnergyPlus simulations). Additionally in Figure 4 the maximum sensitivity index s, calculated according to equation (2), is reported for each kind of variation (PoliMI-TRNSYS simulations). The combination of the most influential variations resulted in several acceptable solutions listed in Table 5, obtained with 2, 3 or 4 variations. It can be noticed that all of them requires the modelling of additional internal mass, either through a lumped capacity approach applied to the air volume or through an explicit simulation of internal partitions.

\section{Automatic calibration/basic data set results}

The automatic calibration performed by UniTOV using IDA-ICE resulted in a calibrated model with a very good agreement with measured data, namely $R M S E=0.27^{\circ} \mathrm{C}$.

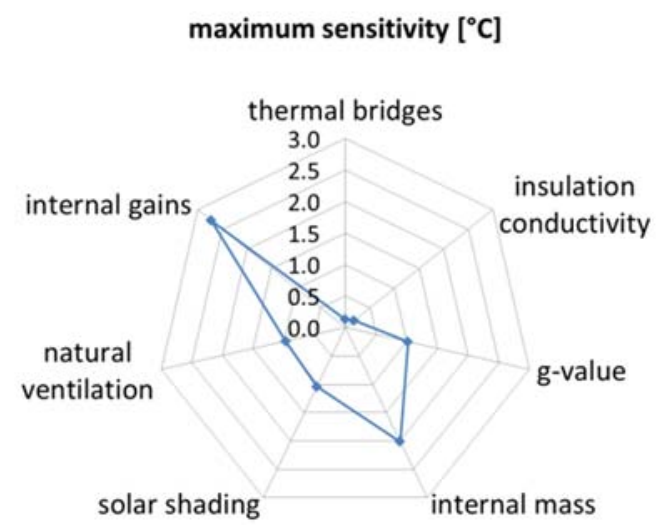

Figure 4: maximum sensitivity of the PoliMI-TRNSYS model to the main parameters

The calibrated parameters are shown in Table 5: the air capacity multiplier is set to 11 , a modest thermal bridges correction is applied, a small amount of natural ventilation $\left(0.08 \mathrm{~h}^{-1}\right)$ is added to the base mechanical ventilation rate $\left(0.5 \mathrm{~h}^{-1}\right)$. The internal gains profile is modified with respect to the base one according to a profile named UniTOV and shown in Figure 5 together with those resulting from the calibrations performed by the other groups. Different solar irradiance thresholds for shutters activation are found for different orientation of

Table 5: calibrated models PoliTO, PoliMI and UniTOV

\begin{tabular}{|c|c|c|c|c|c|c|c|}
\hline & Model & Internal mass & $\begin{array}{l}\text { Thermal } \\
\text { bridges } \\
\text { correction }\end{array}$ & $\begin{array}{c}\text { Natural } \\
\text { ventilation }\end{array}$ & $\begin{array}{c}\text { Internal } \\
\text { gains }\end{array}$ & Solar shading & $\begin{array}{c}\text { RMSE } \\
{\left[{ }^{\circ} \mathrm{C}\right]}\end{array}$ \\
\hline \multirow{4}{*}{ 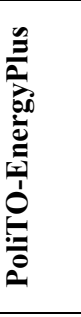 } & PoliTO 1 & $\begin{array}{c}\mathrm{ACM}=5 \\
\mathrm{~S}_{\text {part }}=259 \mathrm{~m}^{2}\end{array}$ & - & $\begin{array}{c}\mathrm{ACH}_{\mathrm{NV}}=0.5 \\
1 \text { p.m. }-10 \text { p.m. }\end{array}$ & - & $\mathrm{G}_{\min }=300 \mathrm{~W} / \mathrm{m}^{2}$ & 0.51 \\
\hline & PoliTO 2 & $\begin{array}{c}\mathrm{ACM}=5 \\
\mathrm{~S}_{\text {part }}=259 \mathrm{~m}^{2}\end{array}$ & - & $\begin{array}{c}\mathrm{ACH}_{\mathrm{NV}}=0.5 \\
1 \text { p.m. }-10 \text { p.m. }\end{array}$ & $\begin{array}{l}\text { Profile } \\
\text { PoliTO }\end{array}$ & $\mathrm{G}_{\min }=300 \mathrm{~W} / \mathrm{m}^{2}$ & 0.43 \\
\hline & PoliTO 3 & $\begin{array}{c}\mathrm{ACM}=8 \\
\mathrm{~S}_{\text {part }}=0\end{array}$ & - & $\begin{array}{c}\mathrm{ACH}_{\mathrm{NV}}=0.5 \\
1 \text { p.m. }-10 \text { p.m. }\end{array}$ & $\begin{array}{l}\text { Profile } \\
\text { PoliTO }\end{array}$ & $\mathrm{G}_{\min }=300 \mathrm{~W} / \mathrm{m}^{2}$ & 0.44 \\
\hline & PoliTO 4 & $\begin{array}{c}\mathrm{ACM}=5 \\
\mathrm{~S}_{\text {part }}=259 \mathrm{~m}^{2}\end{array}$ & - & $\begin{array}{c}\mathrm{ACH}_{\mathrm{NV}}=0.5 \\
11 \text { a.m. }-9 \text { p.m. }\end{array}$ & $\begin{array}{l}\text { Profile } \\
\text { PoliTO }\end{array}$ & $\mathrm{G}_{\min }=300 \mathrm{~W} / \mathrm{m}^{2}$ & 0.38 \\
\hline \multirow{6}{*}{ 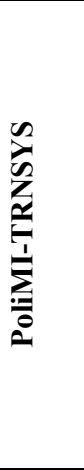 } & PoliMI 1 & $\begin{array}{c}\mathrm{ACM}=5 \\
\mathrm{~S}_{\mathrm{part}}=259 \mathrm{~m}^{2}\end{array}$ & - & - & - & $\mathrm{G}_{\min }=200 \mathrm{~W} / \mathrm{m}^{2}$ & 0.49 \\
\hline & PoliMI 2 & $\begin{array}{c}\mathrm{ACM}=3 \\
\text { Spart }=1034 \mathrm{~m}^{2}\end{array}$ & - & - & - & $\mathrm{G}_{\min }=200 \mathrm{~W} / \mathrm{m}^{2}$ & 0.46 \\
\hline & PoliMI 3 & $\begin{array}{c}\mathrm{ACM}=5 \\
\mathrm{~S}_{\text {part }}=259 \mathrm{~m}^{2}\end{array}$ & - & $\begin{array}{c}\mathrm{ACH}_{\mathrm{NV}}=0.5 \\
1 \text { p.m. }-10 \text { p.m. }\end{array}$ & - & $\mathrm{G}_{\min }=300 \mathrm{~W} / \mathrm{m}^{2}$ & 0.50 \\
\hline & PoliMI 4 & $\begin{array}{c}\mathrm{ACM}=5 \\
\mathrm{~S}_{\text {part }}=259 \mathrm{~m}^{2}\end{array}$ & - & $\begin{array}{l}\mathrm{ACH}_{\mathrm{NV}}=1.5 \\
\text { if } \mathrm{T}_{\mathrm{ext}}>18^{\circ} \mathrm{C}\end{array}$ & - & $\mathrm{G}_{\min }=200 \mathrm{~W} / \mathrm{m}^{2}$ & 0.46 \\
\hline & PoliMI 5 & $\begin{array}{c}\mathrm{ACM}=3 \\
\mathrm{~S}_{\text {part }}=1034 \mathrm{~m}^{2}\end{array}$ & - & $\begin{array}{l}\mathrm{ACH}_{\mathrm{NV}}=1.5 \\
\text { if } \mathrm{T}_{\mathrm{ext}}>16^{\circ} \mathrm{C}\end{array}$ & $\begin{array}{l}\text { Base reduced } \\
\text { by } 25 \%\end{array}$ & - & 0.42 \\
\hline & PoliMI 6 & $\begin{array}{c}\mathrm{ACM}=3 \\
\mathrm{~S}_{\text {part }}=1034 \mathrm{~m}^{2}\end{array}$ & - & $\begin{array}{c}\mathrm{ACH}_{\mathrm{NV}}=0.5 \\
1 \text { p.m. }-10 \text { p.m. }\end{array}$ & $\begin{array}{l}\text { Base reduced } \\
\text { by } 25 \%\end{array}$ & - & 0.42 \\
\hline 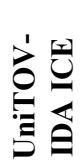 & UniTOV & $\mathrm{ACM}=11$ & $\begin{array}{c}\Psi L=0.32 \\
W / K\end{array}$ & $\mathrm{ACH}_{\mathrm{NV}}=0.08$ & $\begin{array}{l}\text { Profile } \\
\text { UniTOV }\end{array}$ & $\begin{array}{l}\mathrm{G}_{\min }=350 \mathrm{~W} / \mathrm{m}^{2} \mathrm{~N} \\
\mathrm{G}_{\min }=65 \mathrm{~W} / \mathrm{m}^{2} \mathrm{E} \\
\mathrm{G}_{\min }=611 \mathrm{~W} / \mathrm{m}^{2} \mathrm{~S} \\
\mathrm{G}_{\min }=64 \mathrm{~W} / \mathrm{m}^{2} \mathrm{~W}\end{array}$ & 0.27 \\
\hline
\end{tabular}


Table 6: UniTN-TRNSYS calibration of the external wall: base and calibrated properties

\begin{tabular}{|c|c|c|c|c|c|c|}
\hline & \multicolumn{3}{|c|}{ Base properties } & \multicolumn{3}{|c|}{$\begin{array}{l}\text { (Calibrated - base) } \\
\text { base }\end{array}$} \\
\hline $\begin{array}{l}\mathbf{s} \\
\mathbf{c m}\end{array}$ & $\begin{array}{l}\rho \\
\mathrm{kg} / \mathrm{m}^{3}\end{array}$ & $\begin{array}{l}\text { c } \\
\text { J/(kg.K) }\end{array}$ & $\begin{array}{l}\lambda \\
\mathbf{W} /(\mathrm{m} . \mathrm{K})\end{array}$ & $\begin{array}{l}\Delta \rho \\
{[\%]}\end{array}$ & $\begin{array}{l}\Delta \mathrm{c} \\
{[\%]}\end{array}$ & $\begin{array}{l}\Delta \lambda \\
{[\%]}\end{array}$ \\
\hline 6 & 160 & 2100 & 0,050 & -29 & -3 & 1 \\
\hline 1,8 & 550 & 1221 & 0,098 & -56 & 7 & -2 \\
\hline 18 & 40 & 1030 & 0,038 & -9 & -12 & -2 \\
\hline 1,8 & 550 & 1221 & 0,098 & -56 & 7 & -2 \\
\hline 6 & 50 & 2100 & 0,038 & -27 & 1 & 0 \\
\hline 1,5 & 1200 & 1100 & 0,320 & -47 & -5 & 0 \\
\hline
\end{tabular}

Table 7: UniTN-TRNSYS calibration of the building model: parameters range and calibrated values

\begin{tabular}{|c|c|c|}
\hline & Range & Calibrated \\
\hline Solar irrad. shading closed Ap. A & $200-1400$ & $200 \mathrm{~W} \mathrm{~m}^{-2}$ \\
\hline Solar irrad.shading closed Ap. B & $200-1400$ & $300 \mathrm{~W} \mathrm{~m}^{-2}$ \\
\hline Solar irrad. shading closed Ap. C & $200-1400$ & $1400 \mathrm{~W} \mathrm{~m}^{-2}$ \\
\hline $\begin{array}{l}\text { Solar irrad. difference shading } \\
\text { closed-open Ap. A }\end{array}$ & $0-200$ & $200 \mathrm{~W} \mathrm{~m}^{-2}$ \\
\hline $\begin{array}{l}\text { Solar irrad. difference shading } \\
\text { closed-open Ap. B }\end{array}$ & $0-200$ & $200 \mathrm{~W} \mathrm{~m}^{-2}$ \\
\hline $\begin{array}{l}\text { Solar irrad. difference shading } \\
\text { closed-open Ap. C }\end{array}$ & $0-200$ & $50 \mathrm{~W} \mathrm{~m}^{-2}$ \\
\hline $\begin{array}{c}\text { Window opening angle Ap. A } \\
\text { Zone KS }\end{array}$ & $10-90$ & $10 \mathrm{deg}$ \\
\hline $\begin{array}{c}\text { Window opening angle Ap. A } \\
\text { Zone WC } \\
\end{array}$ & $10-90$ & $40 \mathrm{deg}$ \\
\hline $\begin{array}{c}\text { Window opening angle Ap. A } \\
\text { Zone LS }\end{array}$ & $10-90$ & $10 \mathrm{deg}$ \\
\hline $\begin{array}{c}\text { Window opening angle Ap. A } \\
\text { Zone LM }\end{array}$ & $10-90$ & $10 \mathrm{deg}$ \\
\hline $\mathrm{ACH}_{\mathrm{NV}}$ Ap. B/ Ap. A & $0-1.5$ & 0,5 \\
\hline ACHNV Ap. C/ Ap. A & $0-1.5$ & 0 \\
\hline $\mathrm{ACH}$ & $0.5-0.65$ & 0,55 \\
\hline Stairwell zone infiltration $\mathrm{ACH}$ & $0.1-0.6$ & 0,3 \\
\hline$\left(T_{\text {supply }}-T_{\text {ext }}\right)$ Ap. B/Ap. A & $0.5-1.5$ & 0,5 \\
\hline$\left(\mathrm{T}_{\text {supply}}-\mathrm{T}_{\text {ext }}\right)$ Ap. C/Ap. A & $0.5-1.5$ & 0,5 \\
\hline $\begin{array}{l}\text { Time shift internal gains profile } \\
\text { compared to base profile }\end{array}$ & $-2,+2$ & $-1.167 \mathrm{~h}$ \\
\hline Morning gain ampl. living area & $0.5-1.5$ & 1.1 \\
\hline Afternoon gain ampl. living area & $0.5-1.5$ & 1.3 \\
\hline Evening gain ampl. living area & $0.5-1.5$ & 0.5 \\
\hline Morning gain ampl. sleeping area & $0.5-1.5$ & 0.7 \\
\hline Afternoon gain ampl. sleeping area & $0.5-1.5$ & 1.3 \\
\hline Evening gain ampl. sleeping area & $0.5-1.5$ & 1.5 \\
\hline Air capacity multiplier & 1 & 2.25 \\
\hline
\end{tabular}

the windows. The minimum irradiances resulting from calibration suggest that shutters are used primarily on the East and West facades.

\section{Automatic calibration/detailed data set results}

The calibration of the thermal properties of the external walls (Table 6), obtained from single-wall level analysis, resulted in a negligible modification of the thermal conductivities of the layers, so that the U-value of the wall remains equal to $0.12 \mathrm{~W} /\left(\mathrm{m}^{2} . \mathrm{K}\right)$. The variation of the materials density appears more significant, although base values already allow classifying the wall as "light" one.

The automatic calibration at the building level resulted in the model described in Table 7. It is worth to notice that in the calibrated model shutters are activated on different thresholds for the 3 apartments. Moreover, in Apartment $\mathrm{B}$ natural ventilation flow rates are half the Apartment A flow rates, while in Apartment $\mathrm{C}$ the windows are generally closed. The overall performance of the calibrated model, in terms of mean floor air temperature, is $R M S E=0.46^{\circ} \mathrm{C}$.

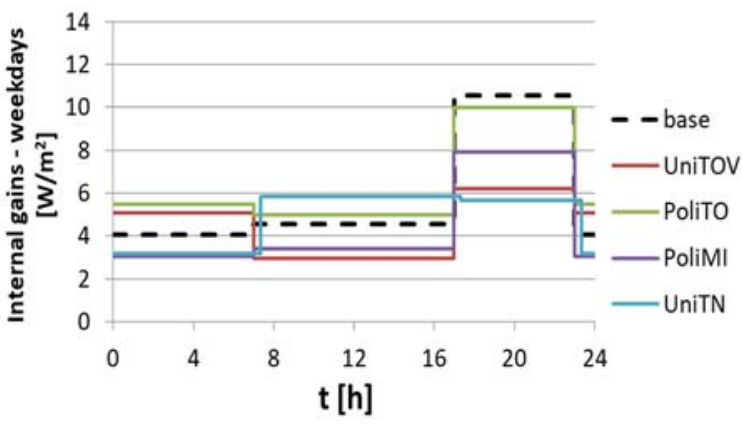

Figure 5: base and calibrated internal gains profiles (weekdays)

\section{Discussion}

Starting from similar results of the base models (Figure2, Table 4), indicating a limited difference in the simulation tools adopted, the research groups came to various calibrated models. The indoor air temperature in the $3^{\text {rd }}$ week of October 2018 simulated by calibrated models obtained by PoliTO (PoliTO 4), PoliMI (PoliMI 5), UniTOV and UniTN is plotted in Figure 6, together with the measured profile. As the corresponding RMSE also demonstrate, it seems that having access to detailed monitoring does not guarantee a better calibration. Indeed, the relatively good performance of the UniTN calibrated model is the result of the combination of a very good performance in predicting the temperature in Apartment A (the one with detailed monitoring) and a less good performance in predicting the air temperature in Apartments B and C. These different performances are shown in (Figure 7) where the simulated temperature is correlated to the measured one for Apartment $\mathrm{A}$ $\left(\mathrm{R}^{2}=0.7135\right)$ and Apartment $\mathrm{B}\left(\mathrm{R}^{2}=0.579\right)$. 
This means that monitoring the windows opening is useful, but it should be extended to most of the users in the building to guarantee an excellent quality of the calibration as a whole.

As the very low RMSE achieved by the UniTOV-IDA ICE model demonstrates, automatic calibration can be more effective than manual one. However, in this case it predicts the substantial absence of natural ventilation due to window opening (Table 5), while monitoring on
Apartment A clearly indicates that windows are open for large part of the day. On the contrary, manual calibration easily results in several possible solutions with comparable performance. However, testing such solutions on a different period can help discriminating among them. As an example, the performance of the models PoliMI 5 and PoliMI 6 (Table 5), calibrated on October 2017, during the $3^{\text {rd }}$ week of August 2018 is shown in Figure 8, where the simulated indoor

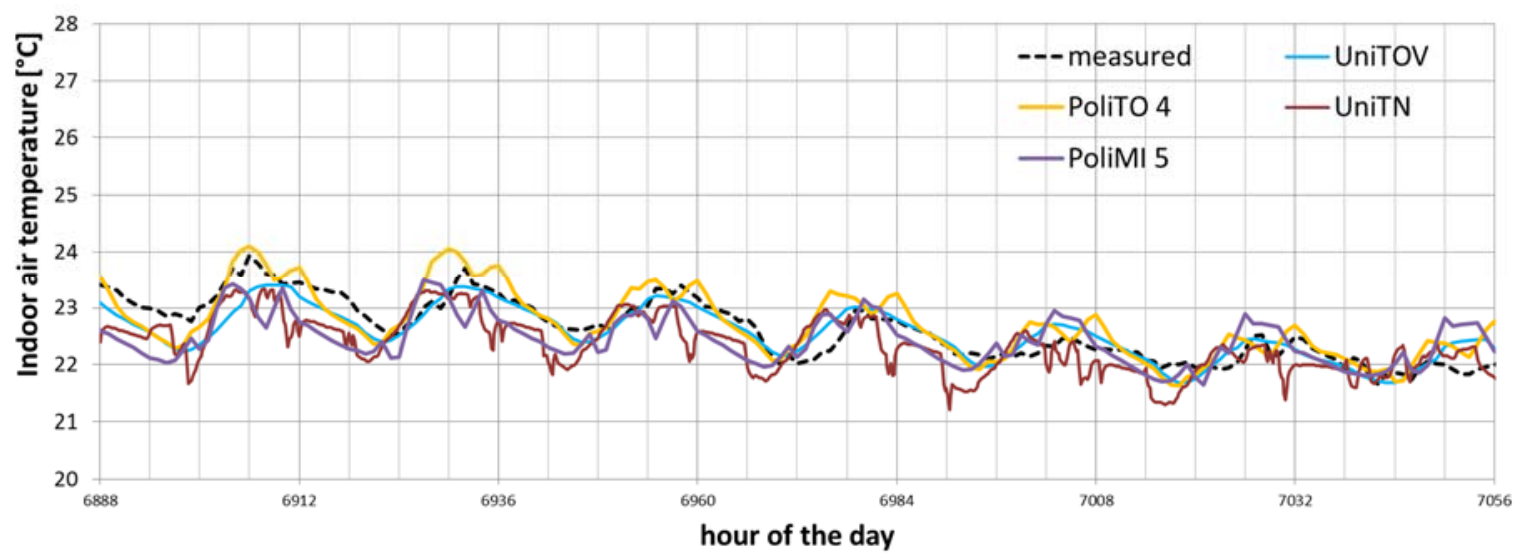

Figure 6: simulated (calibrated models) and measured indoor air temperature ( $3^{\text {rd }}$ week October 2017)
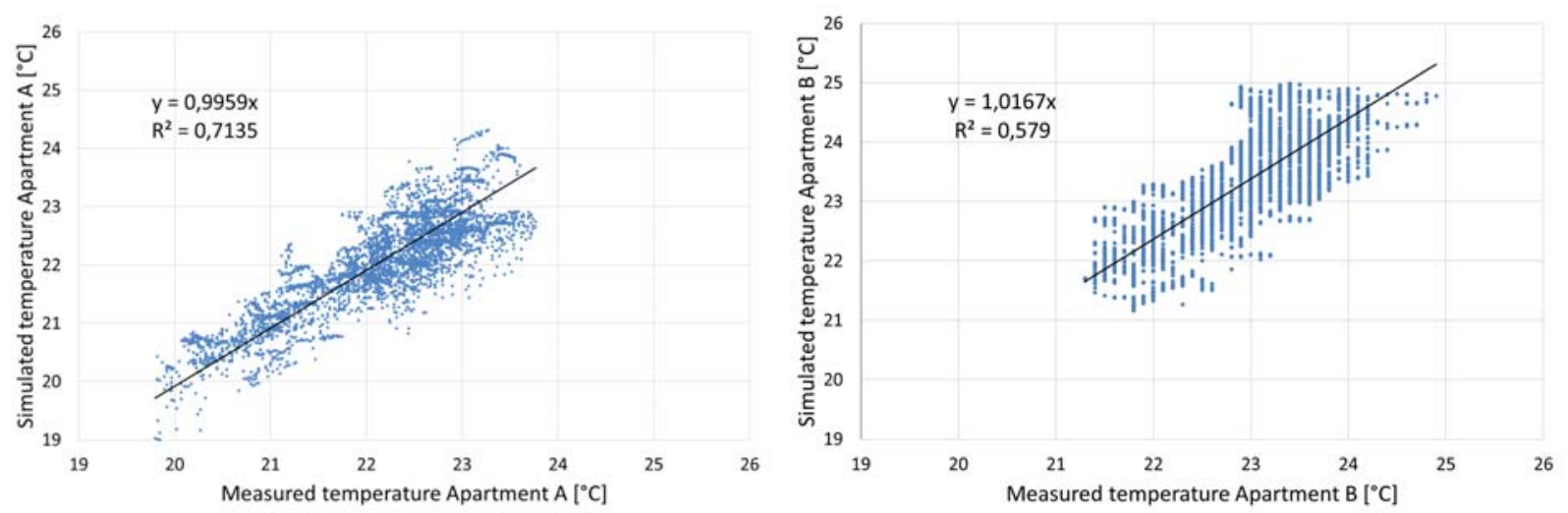

Figure 7: UniTN calibrated model - Apartment A(left) and B(right): simulated vs measured temperature

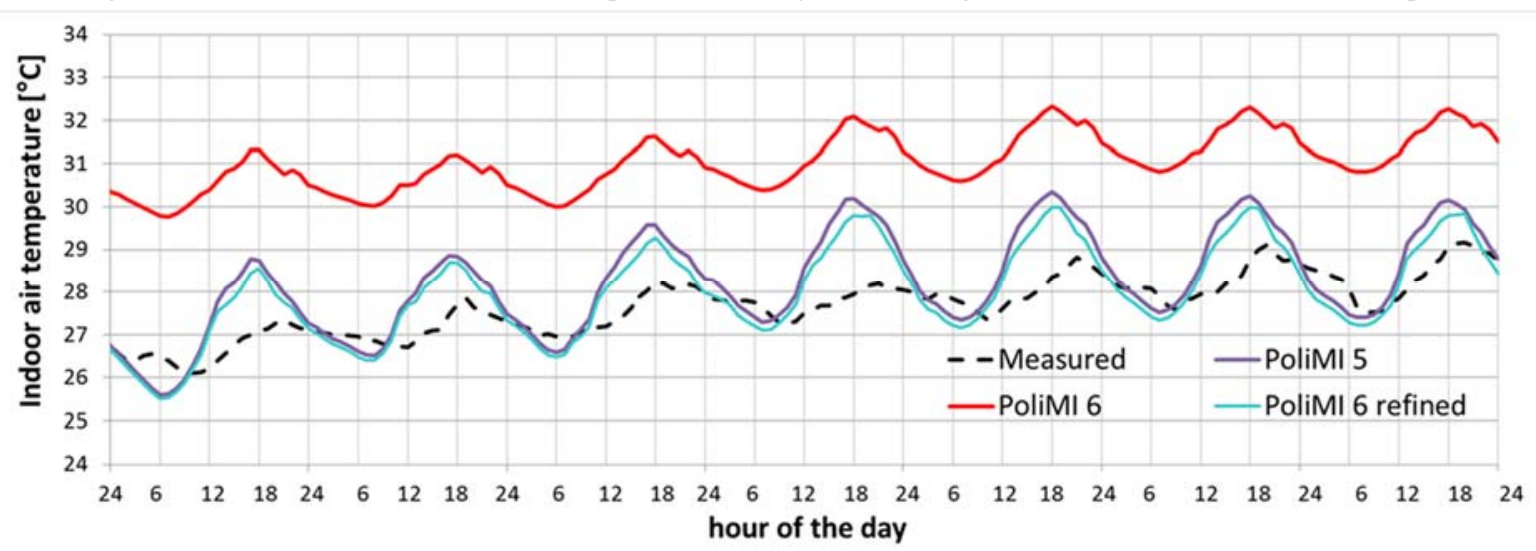

Figure 8: simulated (calibrated models) and measured indoor air temperature (3 $3^{\text {rd }}$ week August 2018) 
temperatures are plotted together with the measured indoor temperature. It can be noticed that the model implementing window opening and natural ventilation according to a schedule (PoliMI 6) has a larger discrepancy compared to the one where window opening is regulated by outdoor temperature (PoliMI 5). Therefore, testing the optimal solutions in August led to discard the solutions of the first kind and to refine the solutions of the second kind. The refinement (PoliMI 6 refined) consisted in the definition of a higher threshold of outdoor temperature regulating the window closing.

As far as internal gains profile is concerned, it can be noticed that calibrated profiles by PoliMI, UniTOV and UniTN, although different (Figure 5), all result in a 24$25 \%$ reduction on the daily energy gain with respect to the base profile.

\section{Conclusions}

A BES model calibration exercise was performed in parallel by different research groups, adopting either manual or automatic calibration and having access to basic or detailed monitoring data.

Manual calibration results in different acceptable combinations of parameters. It was shown that testing such solutions on a different period (validation) can help discriminating among them.

Automatic calibration helps managing the complexity of the parameters involved, identifies a unique and very good performing solution, but in this case such solution is not completely coherent with the evidences regarding user behaviour.

Having access to detailed monitoring data first orientate the development of the building model. For a highly insulated building analysed in free floating conditions, calibrating the opaque envelope properties against monitored data at the single wall level leads to modest adjustments. In turn, monitoring the user behaviour in relation to window opening and using this information lead to more accurate calibration. Therefore, for this kind of buildings, it is more important to invest in monitoring the users' behaviour rather than the envelope thermal response. At the same time users' behaviour is characterised by diversity, so that observations should refer to sufficiently large samples.

In the presence of several acceptable models of an existing building, a possible development of the research will address the question if and to what extent using different calibrated models to design retrofit or management interventions leads to different conclusions.

\section{Acknowledgements}

This research has been carried out within the "Renovation of existing buildings in NZEB vision (nearly Zero Energy Buildings)" Project of National Interest (Progetto di Ricerca di Interesse Nazionale -
PRIN) funded by the Italian Ministry of Education, Universities and Research (MIUR).

\section{References}

Angelotti, A., Martire, M., Mazzarella, L., Pasini, M., Baggio, P., Prada, A., Ballarini, I., Corrado, V., De Luca, G., Bosco, F., Cornaro, C. (2018) Building energy simulation for Nearly Zero Energy retrofit design: the model calibration. Proceedings from 18th EEEIC. Palermo (Italy), 12-15 June 2018.

ASHRAE (2002). Guideline 14:2002. Measurement of Energy and Demand Saving.

Cacabelos, A., Eguia, P., Febrero, L., Granada, E. (2017). Development of a new multi-stage building energy model calibration methodology and validation in a public library, Energy and Buildings 146, 182199.

Coakley, D., Raftery, P., Keane, M. (2014). A review of methods to match building energy simulation models to measured data, Renewable and Sustainable Energy Reviews 37, 123-241.

EN 15242 (2007). Ventilation for buildings - Calculation methods for the determination of air flow rates in buildings including infiltration.

EN ISO 52016-1 (2017). Energy performance of buildings - Energy needs for heating and cooling, internal temperatures and sensible and latent heat loads - Part 1: Calculation procedures.

Fabrizio, E., Monetti. V. (2015). Methodologies and advancements in the calibration of building energy models, Energies 8, 2548-2574.

Gaetani, I., Hoes P.J., Hensen, J.L.M. (2016). Occupant behaviour in building energy simulation: Toward a fit-for-purpose modeling strategy, Energy and Buildings 121, 188-204.

Giovannini, L., Zardi, D., de Franceschi, M. (2013) Characterization of the thermal structure inside an urban canyon: field measurements and validation of a simple model, Journal of Applied Meteorology and Climatology 52, 64-81.

Prada, A., Gasparella, A., Baggio, P. (2019) A robust approach for the calibration of existing buildings models. Proceedings from BS2019 16th Int. Building Simulation Conference. Roma (Italy), 2-4 September 2019.

Yan, D., Hong, T., Dong, B., Mahdavi, A., D’Oca, S., Gaetani, I., Feng, X. (2017). IEA ECB Annex 66: Defintion and simulation of occupant behavior in buildings, Energy and Buildings 156, 258-270.

UNI/TS 11300-1 (2014). Energy performance of buildings Part 1: Evaluation of energy need for space heating and cooling. 